\title{
Comparative Analysis of WASH Services between the Rich and Poor in Sub-Saharan Africa
}

\section{Odafivwotu Ohwo*, Tonye Vivian Odubo}

Department of Geography and Environmental Management, Niger Delta University, Wilberforce Island, Nigeria

Email address:

drohwodafe@gmail.com (O. Ohwo), tonyevodubo@yahoo.com (T. V. Odubo)

${ }^{*}$ Corresponding author

\section{To cite this article:}

Odafivwotu Ohwo, Tonye Vivian Odubo. Comparative Analysis of WASH Services Betweenthe Rich and Poor in Sub-Saharan Africa. International Journal of Natural Resource Ecology and Management. Vol. 6, No. 3, 2021, pp. 147-155. doi: 10.11648/j.ijnrem.20210603.16

Received: July 2, 2021; Accepted: July 29, 2021; Published: August 9, 2021

\begin{abstract}
Achieving the Sustainable Development Goal (SDG) 6 would mean that all people the world over would have access to basic drinking water, sanitation and hygiene (WASH) services. This study analyzed WASH services between the poorest and richest quintile in sub-Saharan Africa (SSA). The descriptive cross sectional design was adopted. Data for the study were extracted from the 2019 Joint Monitoring Programme (JMP) report, which contained disaggregated data on wealth quintiles. The data obtained were analyzed with tables, percentages and t-test. The findings revealed that WASH amenities in SSA were generally poor, especially with the poorest quintile, which was disproportionately disadvantaged. The t-test indicated a significant difference in the provision of WASH services between both quintiles in SSA, as the calculated t-test values for water and sanitation services of 18.772 and 15.317 , respectively were higher than the table value of 2.021 at an alpha level of 0.05; while the calculated t-test value (10) for hygiene services was higher than the table value of 2.042 at 0.05 alpha level. Considering the state of WASH facilities, SSA would miss the SDG 6, unless concerted efforts are made to address the myriad of challenges confronting the provisions of WASH services in SSA. The study therefore made recommendations to address the challenges.
\end{abstract}

Keywords: Hygiene, Inequality, Sanitation, Water, Wealth Quintile

\section{Introduction}

The consequences of poor WASH services are well documented in literature [1]. Inadequate WASH services have been largely blamed for waterborne diseases, which have increased the burden on public health with dire implications on socio-economic development [2]. Hence, addressing WASH related issues is a path-way to ensuring a clean environment, good health and human dignity [3]. Since, SDG 6 focused on providing basic WASH amenities for all by 2030, to achieve this lofty goal, all existing forms of inequalities to adequate WASH services have to be addressed. So far, appreciable successes have been recorded globally through the MDGs and the current SDGs, as the JMP data on water shows that within 17years (2000-2017) the number of people using safely managed water services increased by $10 \%(61-71 \%)$. Similarly, in SSA the number of people having basic water services increased from $46 \%$ to $61 \%$; while surface water dropped from 123 million (19\%) to
82 million (8\%) [4].

Although the JMP data on sanitation from 2000-2017 is not as encouraging as that of drinking water, however, there was $17 \%(28-45 \%)$ increase in safely managed services globally; while in SSA, it increased from $23 \%-31 \%$; and open defecation (OD) practice decreased from $32 \%$ to $20 \%$ [4]. The inability of the JMP to obtain sufficient data has made it difficult to estimate global trends in hygiene services since 2000. However, globally in 2017, about 4.5 billion $(60 \%)$ people had basic hygiene facilities; while it was $25 \%$ in SSA [4].

Despite the reported progress made on the provision of WASH amenities at both the global and regional levels, it has been observed that such progress masked the disparities and inequalities that exist in reality among and within countries [5]. Although WASH services improved from 2000-2017, however, there are significant inequalities in service levels as many people remain without service [4]. Unfortunately, different forms of WASH inequalities (rich and poor; able 
and disabled; male and female, etc) can be found in all countries, but difficult to carry out some of these analyses due to insufficient disaggregated data [6]. Wealth differentials are major forms of inequalities that reinforce the disparities that exist in WASH services globally. Hence, the spread in coverage among wealth quintiles is a fundamental determinant of how equitable services are [6]. The rich tend to have better WASH services than their poor counterparts, as the analysis across countries suggests that wealth is the major determinant of WASH status, and that wealthier people have more chances of piped water on premises than their poor counterparts [7]. This shows that WASH services favoured the rich, which could further exacerbate the already existing inequality, which could threaten the realization of SDG 6.

To actualize the SDG 6 , it is imperative to continuously focus and analyze the level of service of the bottom 40 quintiles (poor and poorest) everywhere and regions of the world. Hence, this study is aimed at analyzing the WASH services between the poorest and richest quintiles in SSA. This will reveal whether the gap in WASH services among wealth quintiles are being progressively abridged and the access of everyone to basic WASH services is being enhanced. Studies of this nature could reveal the inherent inequalities in WASH services in SSA and guide policy direction on development of appropriate strategies to achieve SDG 6 by 2030 in the region [8].

\section{Method of Study}

This paper is aimed at conducting a comparative study of WASH services among wealth quintiles in SSA. The comparative analysis was carried out using secondary data obtained from UNICEF and WHO, JMP report, which contain data on household WASH services from 2000-2017 [4]. From the JMP global data, the disaggregated WASH status between the poorest and richest quintiles in SSA region were extracted and used for the analysis. The extracted data were analyzed with descriptive statistics (tables, charts and percentages), while the t-test statistic was employed to test the significant difference in WASH services between the quintiles in SSA. The test was conducted separately for each WASH service, respectively. The analysis was restricted to countries that had disaggregated (richest and poorest) WASH data from 2000-2017. Therefore, the analysis involved 39 countries that had disaggregated data for water and sanitation; while 30 countries only for hygiene. The findings from the analysis of data from these countries were used to generalize WASH services among wealth quintiles in SSA.

\section{Results and Discussion}

\subsection{Water Service Levels by Wealth Quintile in SSA}

The analysis of water services was carried out using four rating scales: at least basic, limited, unimproved and surface water, as indicated in Table 1. The data in the table shows that in all the $39(100 \%)$ countries included in the study, a higher proportion of water services were recorded among the richest quintile than their poorest counterparts in 2017, which clearly indicated that there exist inequalities in water services in SSA. The range for basic services was $73-99 \%$ among the richest quintile, with Niger (73\%) and Namibia (99\%) coverage. For the poorest quintile, the range was $15-80 \%$, with DR Congo and Sao Tome \& Principe having the lowest (15\%) and highest (80\%), respectively. This further confirms the existence of wealth quintile inequality in SSA. In some countries, the inequality gap is so wide to the advantage of the rich. For example, in Angola and DR Congo, basic drinking water services was 17:94\% (inequality gap of 77\%) and $15: 85 \%$ (inequality gap of $70 \%$ ) to the advantage of the richest quintile, respectively. In fact, 30 (76.92\%) countries had an inequality gap of $35 \%$ and above in favour of the richest quintile.

Since the richest quintile had better water services compared to their poorest counterparts, it is therefore not surprising that $<1 \%$ of them use surface water in 33 $(84.62 \%)$ countries studied. However, among the poorest, surface water was still widely used in SSA. In 20 (51.28\%) countries, $15 \%$ and above of the poorest use surface water (Table 1), which is the worst source of water supply using the JMP ladder [6]. Also, limited and unimproved water sources usage was more prevalent among the poorest. The use of limited water service ranges from $2-42 \%$ among the poorest quintile, with Uganda having $42 \%$, while Sierra Leone $2 \%$. Furthermore, $10 \%$ and above of the poorest use limited services in $22(56.41 \%)$ countries; while among the richest, limited water services range from $<1-17 \%$, with Burundi having the highest $(17 \%)$ and three countries-Namibia, Senegal and Sudan, with the lowest $(<1 \%)$. In addition, $10 \%$ and above of the richest quintile used limited water sources in $12(30.77 \%)$ countries in SSA.

Several studies have established that water services for the rich are better than for the poor $[7,8,10,11]$. However, access of wealth quintile to water services is often determined by location (urban, peri urban or rural). Hence, it has been asserted that rurality explains $45 \%$ of poor water services [12]. Another study lay credence to this assertion that urban poor households have $29 \%$ and $25 \%$ better access to water and sanitation services, respectively, than rural poor households, which indicates that in spite of the closeness of the urban poor to basic WASH services, however, they face affordability challenges, compared to those in rural areas who might completely lack these facilities [13]. Similarly, it was reported that poor households in bigger cities have better WASH facilities than households in small-towns at the same or even higher income [9]. This shows that wealth status and location are major factors that determine water services in SSA. For instance a survey revealed that in Nigeria water services are progressively better as the wealth status improves and from itinerant to urban area [14]. For example, the poorest had $46 \%$ service level, poor $59 \%$, middle $69 \%$, rich $80 \%$ and richest $91 \%$; while for location, itinerant $45 \%$, rural $60 \%$, small town $69 \%$, peri urban $78 \%$ and urban $89 \%$. With these statistics, more efforts should be directed at the 
poor and rural households to bridge the gaps in wealth quintile and rural-urban inequalities.

A further analysis of progress in water services from 20002017 revealed that in some countries service levels retrogressed in both the poorest and richest quintiles. For example, six countries (Angola, CAR, Comoros, Rwanda, Sudan and Zimbabwe) experienced reduction in water services among the poorest from 2000-2017 (Figure 1). The highest reduction coverage was recorded in Sudan, from $47 \%$ in 2000 to $35 \%$ in 2017 (a $12 \%$ reduction); while the others range from $1-10 \%$. Among the richest quintile, seven countries (Benin, CAR, Comoros, Gabon, Ghana, Madagascar and Sudan) experienced reduced proportion to water services from 2000- 2017. Although more countries (7) experienced reduction in services among the richest quintile than the poorest quintile (6), however, the range of reduction (1-6\%) was less with the richest than the poorest range (1$12 \%)$. Madagascar had the highest reduction $(6 \%)$ in basic water services among the richest quintile (Figure 2). Irrespective of the degree of reduction, the fundamental issue is that progress was not made in water services in the affected countries from 2000-2017, despite the general progress experienced globally. Hence, the calculated t-test indicated the existence of a significant difference in water services between the poorest and richest quintiles in SSA, as the calculated t-test value of 18.772 was higher than the table value of 2.021 at an alpha level of 0.05 . From the above analyses, it can be said that the existing inequalities are hidden in global, regional and national averages, which assumes everyone is being carried along, whereas the poorest are disproportionately disadvantaged in SSA. This portends a serious threat to the actualization of SDG 6.1 as it appears that the poor in SSA are being left behind. The reasons for this retrogression should be attended to in the affected countries if the SDG 6.1 is to be realized.

Table 1. Water Service Levels by Wealth Quintile in SSA, 2017.

\begin{tabular}{|c|c|c|c|c|c|c|c|c|c|}
\hline \multirow{3}{*}{$\mathbf{S} / \mathbf{N}$} & \multirow{3}{*}{ Country } & \multicolumn{8}{|c|}{ Drinking Water Sources } \\
\hline & & \multicolumn{2}{|c|}{ At least basic (\%) } & \multicolumn{2}{|c|}{ Limited >30mins (\%) } & \multicolumn{2}{|c|}{ Unimproved (\%) } & \multicolumn{2}{|c|}{ Surface water (\%) } \\
\hline & & Poorest & Richest & Poorest & Richest & Poorest & Richest & Poorest & Richest \\
\hline 1 & Angola & 17 & 94 & 7 & 6 & 20 & $<1$ & 56 & $<1$ \\
\hline 2 & Benin & 56 & 90 & 10 & 1 & 23 & 9 & 12 & $<1$ \\
\hline 3 & Burkina Faso & 49 & 88 & 20 & 9 & 23 & 3 & 8 & $<1$ \\
\hline 4 & Burundi & 56 & 79 & 25 & 17 & 16 & 4 & 3 & $<1$ \\
\hline 5 & Cameroon & 40 & 94 & 9 & 5 & 36 & $<1$ & 16 & $<1$ \\
\hline 6 & CAR & 42 & 75 & 11 & 13 & 39 & 11 & 8 & $<1$ \\
\hline 7 & Chad & 25 & 83 & 11 & 9 & 47 & 7 & 18 & $<1$ \\
\hline 8 & Comoros & 76 & 93 & 8 & 1 & 14 & 6 & 2 & $<1$ \\
\hline 9 & Congo & 34 & 85 & 8 & 13 & 30 & 1 & 28 & $<1$ \\
\hline 10 & Côte d'Ivoire & 53 & 98 & 9 & 1 & 26 & $<1$ & 11 & $<1$ \\
\hline 11 & DR Congo & 15 & 85 & 8 & 10 & 62 & 5 & 15 & $<1$ \\
\hline 12 & Ethiopia & 27 & 86 & 18 & 11 & 39 & 3 & 17 & $<1$ \\
\hline 13 & Gabon & 58 & 96 & 21 & 2 & 5 & 2 & 16 & $<1$ \\
\hline 14 & Gambia & 68 & 95 & 13 & 3 & 19 & 1 & $<1$ & $<1$ \\
\hline 15 & Ghana & 54 & 94 & 12 & 2 & 9 & 4 & 25 & $<1$ \\
\hline 16 & Guinea & 57 & 95 & 9 & 5 & 19 & $<1$ & 16 & $<1$ \\
\hline 17 & Guinea-Bissau & 48 & 89 & 4 & 4 & 47 & 6 & $<1$ & $<1$ \\
\hline 18 & Kenya & 37 & 92 & 13 & 3 & 14 & 3 & 37 & 2 \\
\hline 19 & Lesotho & 56 & 91 & 9 & 6 & 34 & 3 & 2 & $<1$ \\
\hline 20 & Liberia & 56 & 91 & 3 & 6 & 5 & 2 & 36 & $<1$ \\
\hline 21 & Madagascar & 20 & 82 & 2 & 2 & 52 & 14 & 26 & 3 \\
\hline 22 & Malawi & 61 & 84 & 22 & 13 & 14 & 3 & 3 & $<1$ \\
\hline 23 & Mali & 53 & 96 & 4 & 4 & 40 & $<1$ & 3 & $<1$ \\
\hline 24 & Mauritania & 34 & 86 & 25 & 14 & 39 & $<1$ & 2 & $<1$ \\
\hline 25 & Mozambique & 34 & 94 & 15 & 5 & 30 & 1 & 21 & $<1$ \\
\hline 26 & Namibia & 57 & $>99$ & 12 & $<1$ & 15 & $<1$ & 16 & $<1$ \\
\hline 27 & Niger & 45 & 73 & 23 & 13 & 31 & 13 & $<1$ & 1 \\
\hline 28 & Nigeria & 38 & 95 & 7 & 4 & 40 & $<1$ & 15 & $<1$ \\
\hline 29 & Rwanda & 43 & 77 & 23 & 14 & 24 & 6 & 10 & 3 \\
\hline 30 & Sao Tome \&Principe & 80 & 90 & 13 & 10 & 1 & $<1$ & 6 & $<1$ \\
\hline 31 & Senegal & 48 & 98 & 9 & $<1$ & 42 & 1 & $<1$ & $<1$ \\
\hline 32 & Sierra Leone & 38 & 82 & 2 & 14 & 26 & 3 & 34 & $<1$ \\
\hline 33 & Somalia & 32 & 93 & 40 & 7 & 25 & $<1$ & 3 & $<1$ \\
\hline 34 & Sudan & 35 & 96 & 20 & $<1$ & 45 & 3 & $<1$ & $<1$ \\
\hline 35 & Tanzania & 24 & 87 & 13 & 7 & 42 & 4 & 20 & 2 \\
\hline 36 & Togo & 34 & 95 & 6 & 2 & 28 & 2 & 33 & $<1$ \\
\hline 37 & Uganda & 34 & 77 & 42 & 17 & 14 & 4 & 10 & 3 \\
\hline 38 & Zambia & 34 & 93 & 6 & 2 & 41 & 4 & 19 & $<1$ \\
\hline 39 & Zimbabwe & 39 & 96 & 14 & 3 & 30 & $<1$ & 17 & $<1$ \\
\hline
\end{tabular}

Source: Adapted from [4] 


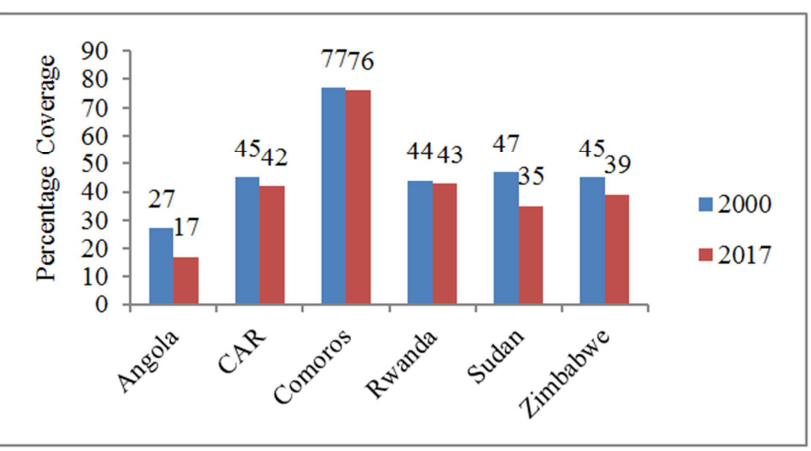

Source: Adapted from [4]

Figure 1. Countries with Reduced Proportion of Poorest Quintile to Basic Water Services in SSA, 2000 - 2017.

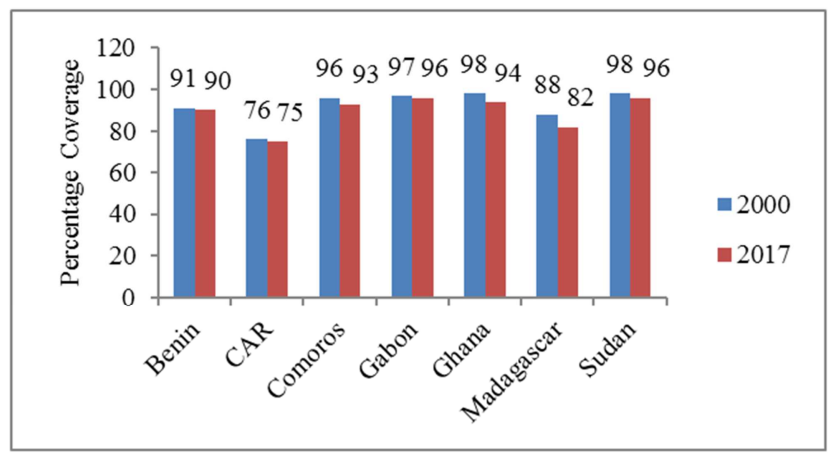

Source: Adapted from [4]

Figure 2. Countries with Reduced Proportion of Richest Quintile to Basic Water Services in SSA, 2000 - 2017.

\subsection{Sanitation Service Levels by Wealth Quintile in SSA}

The various levels of sanitation services (at least basic, limited, unimproved and open defecation) by wealth quintile in SSA are indicated in Table 2. As earlier mentioned, the progress on sanitation at the global level and SSA lagged behind the successes attained when compared to drinking water, as only $31 \%$ had basic sanitation in 2017 [4]. This implies that $69 \%$ use unsatisfactory sanitation facilities, which could pose great danger to public health.

Despite the general low basic sanitation coverage, there exist deep and profound inequalities in SSA. The most obvious inequalities are between the poor and rich and urban and rural areas. Table 2 reveals that in all the 39 (100\%) countries studied, sanitation services were better with the richest quintile. The access range with the poorest quintile in SSA in 2017 was $<1-48 \%$, with Rwanda having the highest $(48 \%)$ coverage, while the lowest $(<1 \%)$ was recorded in Benin, CAR and Chad; while the range of coverage for the richest was $17-88 \%$, with Angola having the highest (88\%) coverage and Madagascar the lowest (17\%) coverage (Table 2). This simply means that the difference between both minimum and maximum values between the rich and poor are about 16 and 40 percentage points, respectively.

Table 2 also revealed that the highest disparity in sanitation services (4-87\%) between the poorest and richest quintiles, which represents $83 \%$ difference, was recorded in Namibia; while Madagascar with 2-17\% (15\%) difference had the lowest, all in favour of the richest quintile. Thus, accessing basic sanitation is a heavy burden on the poor thereby creating a wide gap on wealth quintile inequalities. This situation could negatively affect the attainment of SDG 6.2 in SSA and further thwart the efforts of national governments in poverty reduction.

The coverage pattern for limited (shared) sanitation was similar to that of 'at least basic'. Apart from Comoros and Gabon, that had $8-5 \%$ and $25-8 \%$ coverage, respectively, in favour of the poorest quintile, in all other counties, the coverage was in favour of the richest quintile (Table 2). The range among the poorest quintile for limited sanitation was $<$ 1- 25\%, with Gabon having the highest (25\%) coverage, while CAR and Chad had the lowest $(<1 \%)$. Among the richest quintile, the range was $5-53 \%$, with Comoros $(5 \%)$ and Sierra Leone (53\%) coverage, respectively. The proportion of the population that used unimproved sanitation was higher with the poorest quintile. For example, in 32 $(82.05 \%)$ countries in the region, the poorest quintile had the highest number of people with unimproved sanitation, with a range of $<1-69 \%$. Lesotho had the lowest $(<1 \%)$ proportion, while Uganda had the highest (69\%). On the other hand, the range among the richest quintile was $<1-50 \%$, with Ethiopia having the highest $(50 \%)$ proportion and Angola, CAR, Senegal and Sao Tome and Principe, with the lowest $(<1 \%)$. The practice of open defecation (OD), the worst form of sanitation is very common with the poorest quintile in SSA. For example, 19 (48.72\%) countries had 50\% and above of the poorest population practicing OD. Unfortunately, in some of these countries such as Angola, Ghana, Kenya, Liberia, Madagascar and Mozambique with high rate of OD, also have over $20 \%$ of the poorest quintile using surface water as their major source of drinking water (see Table 1). This shows that the poor stand greater risk of contracting waterborne diseases because of the possibilities of human feces contaminating the surface water sources.

The highest $(92 \%)$ proportion of OD practice among the poorest quintile was recorded in Benin and Namibia, while the lowest $(<1 \%)$ was recorded in Comoros. Also, Comoros had the lowest $(0 \%)$ difference of OD practice between the poorest and the richest quintile, while Namibia had the highest (about 91\%) in favour of the rich. This shows that the wealth quintile inequality gap for OD is most severe in Namibia and non existence in Comoros. Among the richest quintile, OD practice is gradually being eliminated in most countries in the region. For instance, 27 (71.79\%) countries had $<1 \%$ of the richest quintile practicing OD. The country with the highest (16\%) OD practice among the richest quintile was Madagascar (Table 2).

It should be noted at this point that from the analysis of progress made in each country in the region on access to at least basic sanitation services from 2000-2017, it was found that some countries did not just fail to make progress but 
indeed retrogressed either among the poorest or richest quintile or both. For example, 11 countries-Burundi, Cameroon, CAR, Gabon, Gambia, Mali, Mozambique, Senegal, Somalia, Uganda and Zimbabwe had reduced proportion of their poorest quintile to at least basic sanitation services (BSS) in the region from 2000 to 2017 (Figure 3). The highest (19) and lowest (1) percentage point reduction on access to at least BSS were recorded in Cameroon and CAR, respectively. Among the richest quintile, nine countries-Benin, Comoros, Gabon, Gambia, Malawi, Namibia, Niger, Zambia and Zimbabwe experienced reduced proportion to at least basic sanitation services in the region from 2000 to 2017, with Comoros and Gambia having the highest (7) percentage points reduction, while Benin, Gabon, Malawi, Namibia and Zimbabwe, respectively had the lowest (1) percentage point reduction (Figure 4). This shows that much still needs to be done to halt the retrogression and revive growth in basic sanitation provision in the region, especially in countries where reduction in basic services were recorded. The t-test for sanitation equally shows that there exists significant difference in access to BSS between both quintiles in sub-Saharan Africa, as the calculated t-test was 15.317 with a table value of 2.021 at 0.05 alpha level.

It has been reported that access to at least BSS improves from the poorest to the richest quintile [6]. Similarly, in a recent study in Nigeria, the inequality gap in access to at least BSS between the fourth (rich) and fifth (richest) quintile was very large $(43: 71 \%)$. Also, large gap exist in OD practice between the third (middle) and fourth (rich) quintile (30:16\%) and between the fourth (rich) and (fifth) richest quintile (16:2\%); while between the poorest and second (poor) quintile, and second (poor) to third (middle) quintile, the inequality gap $(38: 34: 30 \%)$ was just $4 \%$, respectively [14]. This means that OD dropped significantly from the third to the richest quintile. Knowing these disparities is one of the first fundamental steps in developing strategies to reducing inequalities in service levels between the rich and poor [6].

Table 2. Sanitation Service Levels by Wealth Quintile in SSA, 2017.

\begin{tabular}{|c|c|c|c|c|c|c|c|c|c|}
\hline \multirow{3}{*}{$\mathbf{S} / \mathbf{N}$} & \multirow{3}{*}{ Country } & \multicolumn{8}{|c|}{ Sanitation Facilities } \\
\hline & & \multicolumn{2}{|c|}{ At least basic (\%) } & \multicolumn{2}{|c|}{ Limited (Shared) (\%) } & \multicolumn{2}{|c|}{ Unimproved (\%) } & \multicolumn{2}{|c|}{ Open Defecation (\%) } \\
\hline & & Poorest & Richest & Poorest & Richest & Poorest & Richest & Poorest & Richest \\
\hline 1 & Angola & 12 & 88 & 5 & 12 & 8 & $<1$ & 75 & $<1$ \\
\hline 2 & Benin & $<1$ & 46 & 4 & 36 & 4 & 12 & 92 & 6 \\
\hline 3 & Burkina Faso & 10 & 58 & 13 & 41 & 2 & 1 & 75 & $<1$ \\
\hline 4 & Burundi & 32 & 63 & 5 & 22 & 56 & 14 & 7 & $<1$ \\
\hline 5 & Cameroon & 8 & 74 & 1 & 24 & 60 & 3 & 31 & $<1$ \\
\hline 6 & CAR & $<1$ & 67 & $<1$ & 32 & 31 & $<1$ & 67 & $<1$ \\
\hline 7 & Chad & $<1$ & 36 & $<1$ & 28 & 10 & 25 & 88 & 11 \\
\hline 8 & Comoros & 29 & 54 & 8 & 5 & 62 & 41 & $<1$ & $<1$ \\
\hline 9 & Congo & 3 & 53 & 3 & 38 & 61 & 8 & 33 & $<1$ \\
\hline 10 & Côte d'Ivoire & 5 & 71 & 10 & 22 & 26 & 7 & 58 & $<1$ \\
\hline 11 & DR Congo & 16 & 26 & 14 & 40 & 44 & 33 & 27 & 2 \\
\hline 12 & Ethiopia & 5 & 21 & 1 & 27 & 48 & 50 & 45 & 2 \\
\hline 13 & Gabon & 14 & 86 & 25 & 8 & 55 & 6 & 6 & $<1$ \\
\hline 14 & Gambia & 27 & 72 & 14 & 18 & 55 & 10 & 5 & $<1$ \\
\hline 15 & Ghana & 9 & 45 & 20 & 51 & 19 & 3 & 53 & 1 \\
\hline 16 & Guinea & 8 & 55 & 7 & 43 & 56 & 2 & 28 & $<1$ \\
\hline 17 & Guinea-Bissau & 8 & 44 & 5 & 37 & 33 & 20 & 53 & $<1$ \\
\hline 18 & Kenya & 11 & 51 & 11 & 37 & 36 & 12 & 43 & $<1$ \\
\hline 19 & Lesotho & 28 & 64 & 3 & 29 & $<1$ & 6 & 69 & $<1$ \\
\hline 20 & Liberia & 2 & 58 & 13 & 33 & 16 & 7 & 69 & 2 \\
\hline 21 & Madagascar & 2 & 17 & 4 & 21 & 25 & 46 & 70 & 16 \\
\hline 22 & Malawi & 15 & 41 & 12 & 19 & 59 & 40 & 14 & $<1$ \\
\hline 23 & Mali & 13 & 60 & 3 & 33 & 53 & 7 & 30 & $<1$ \\
\hline 24 & Mauritania & 4 & 78 & 2 & 14 & 4 & 7 & 90 & $<1$ \\
\hline 25 & Mozambique & 8 & 75 & 1 & 14 & 40 & 10 & 50 & $<1$ \\
\hline 26 & Namibia & 4 & 87 & 2 & 10 & 2 & 2 & 92 & $<1$ \\
\hline 27 & Niger & 3 & 36 & 3 & 28 & 8 & 7 & 86 & 29 \\
\hline 28 & Nigeria & 17 & 52 & 3 & 39 & 32 & 5 & 48 & 4 \\
\hline 29 & Rwanda & 48 & 67 & 14 & 28 & 33 & 5 & 6 & $<1$ \\
\hline 30 & Sao Tome \&Principe & 13 & 85 & 5 & 7 & 2 & $<1$ & 80 & 8 \\
\hline 31 & Senegal & 10 & 84 & 4 & 16 & 43 & $<1$ & 44 & $<1$ \\
\hline 32 & Sierra Leone & 3 & 36 & 19 & 53 & 37 & 10 & 40 & 1 \\
\hline 33 & Somalia & 3 & 50 & 2 & 46 & 23 & 3 & 72 & $<1$ \\
\hline 34 & Sudan & 7 & 81 & 1 & 16 & 37 & 3 & 54 & $<1$ \\
\hline 35 & Tanzania & 16 & 57 & 4 & 35 & 52 & 7 & 27 & $<1$ \\
\hline 36 & Togo & 3 & 44 & 5 & 47 & 9 & 6 & 8 & 3 \\
\hline 37 & Uganda & 5 & 43 & 5 & 40 & 69 & 17 & 21 & $<1$ \\
\hline 38 & Zambia & 15 & 64 & 5 & 26 & 48 & 10 & 32 & $<1$ \\
\hline 39 & Zimbabwe & 10 & 65 & 8 & 33 & 17 & 2 & 65 & $<1$ \\
\hline
\end{tabular}

Source: Adapted from [4] 


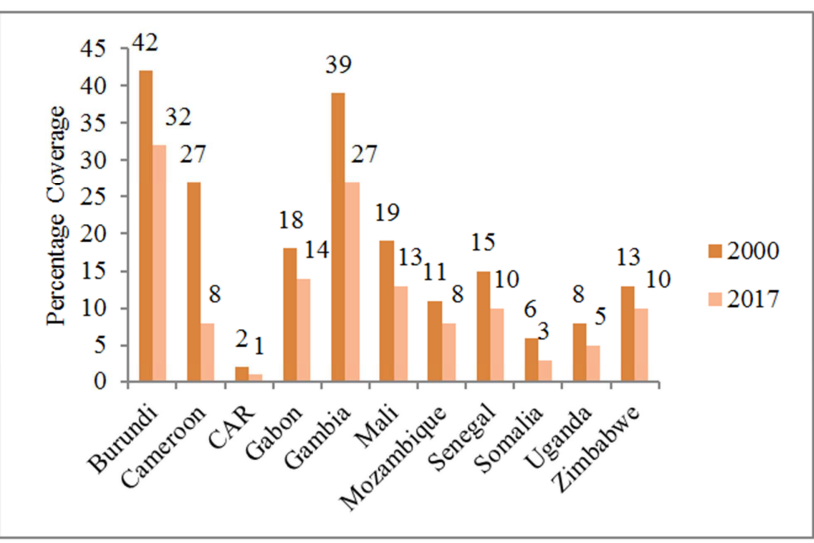

Source: Adapted from [4]

Figure 3. Countries with Reduced Proportion of Poorest Quintile to at Least Basic Sanitation Services in SSA from 2000 to 2017.

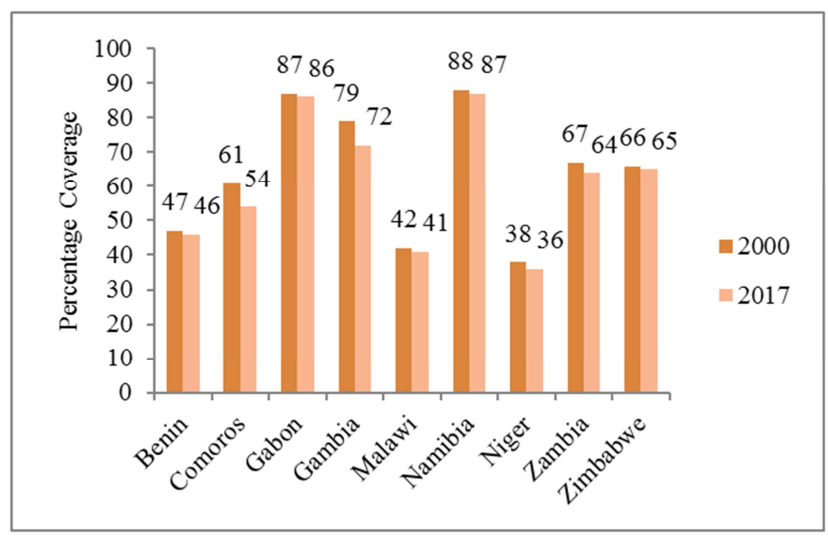

Source: Adapted from [4]

Figure 4. Countries with Reduced Proportion of Richest Quintile to at Least Basic Sanitation Services in SSA from 2000 to 2017.

\subsection{Hygiene Service Levels by Wealth Quintile in SSA}

Table 3 revealed the percentage of the various hygiene service levels-at least basic, limited and no facility, by wealth quintile in SSA. Unlike water and sanitation services, inadequate data had made it impossible to monitor global hygiene services since 2000; hence, progress had been difficult to measure [4]. However, in recent times most countries in SSA have started collecting disaggregated data on hygiene, paving the way for the measurement of progress on hygiene services. In $2017,60 \%, 22 \%$ and $18 \%$ of the world population had access to basic hygiene, limited and no facility at all, respectively. The averages in SSA fell below the global averages, as only $25 \%, 34 \%$ and $41 \%$ of the population, respectively had access to basic hygiene, limited and no hygiene facilities [4]. This shows that progress in hygiene services in SSA has to be doubled to bridge the basic hygiene service gap with the rest of the world.

Data in Table 3 show that the proportions of the richest quintile to at least basic hygiene were more than the poorest in all the $30(100 \%)$ countries studied. Access to basic hygiene among the poorest quintile was not encouraging as only six $(20 \%)$ countries had above $10 \%$ of their respective population with at least basic services; while among the richest quintile, access was better as 19 (63.33\%) countries had over $20 \%$ of their population with at least basic hygiene services. The access range to at least basic hygiene among the poorest and the richest quintiles were $<1-30 \%$ and 5$79 \%$, respectively. The lowest range $(<1 \%)$ among the poorest quintile was recorded in Chad, DR Congo, Gambia, Lesotho, Liberia, Malawi, Rwanda, Sierra Leone and Tanzania; while the highest $(30 \%)$ was recorded in Congo. On the other hand, the lowest range among the richest quintile was recorded in Liberia, while the highest was recorded in Namibia. Although Namibia had the highest range among the richest quintile, surprisingly, it also had the highest inequalities $(17: 79 \%)$ between the poorest and the richest, with a $62 \%$ difference. On the other hand, Liberia had the lowest inequalities $(<1-5 \%)$ between the poorest and the richest, with about $4 \%$ difference. This difference does not necessarily mean better hygiene services but a pointer to general poor national hygiene services.

Access to limited hygiene services between the poorest and richest quintiles was very close. Among the poorest quintile, $14(46.67 \%)$ countries had above $20 \%$ of their population using limited hygiene facilities; while among the richest quintile, it was $15(50 \%)$ countries. However, the range for limited services was $<1-96 \%$ for the poorest quintile. Lesotho had the minimum $(<1 \%)$ and Burundi with the maximum (96\%). Among the richest quintile, the range was $3-82 \%$, with Liberia having the lowest $(3 \%)$ and Burundi with the highest $(82 \%)$. This is a clear indication that there exist great disparities in hygiene services among the countries in the region. Although the proportion of the general population without access to hygiene facilities was very high, however, the proportion of the poorest quintile with no facility was still higher than that of the richest. For example, in $23(76.67 \%)$ countries, over $50 \%$ of the poorest quintile had no hygiene facilities, compared to 9 (30\%) countries among the richest quintile (Table 3). The range for the poorest quintile was $2-99 \%$, with Burundi having the lowest (2\%) figure and Lesotho with the highest (99\%). This shows that hygiene facilities are almost non existence among the poorest quintile in Burundi. This situation may compromise the use of hand washing to combat infectious diseases and the current ravaging COVID-19 pandemic. Among the richest quintile, the range was $<1-93 \%$, with Burundi having the minimum $(<1 \%)$, while Liberia had the maximum (93\%). Senegal had the highest difference (54\%) with no hygiene facilities between the poorest and the richest quintile, while Burundi had the lowest (about 1\%). The t-test result also shows that there exists significant difference in access to basic hygiene services between the richest and poorest quintiles in SSA, as the calculated t-test value was 10 , while the table value was 2.042 , at 0.05 alpha level. 
Table 3. Hygiene Service Levels by Wealth Quintile in SSA, 2017

\begin{tabular}{|c|c|c|c|c|c|c|c|}
\hline \multirow{3}{*}{$\mathbf{S} / \mathbf{N}$} & \multirow{3}{*}{ Country } & \multicolumn{6}{|c|}{ Hygiene Facilities } \\
\hline & & \multicolumn{2}{|c|}{ At least basic (\%) } & \multicolumn{2}{|c|}{ Limited (without water or soap) (\%) } & \multicolumn{2}{|c|}{ No facility (\%) } \\
\hline & & Poorest & Richest & Poorest & Richest & Poorest & Richest \\
\hline 1 & Angola & 9 & 57 & 14 & 11 & 77 & 33 \\
\hline 2 & Benin & 4 & 26 & 11 & 9 & 84 & 65 \\
\hline 3 & Burundi & 2 & 17 & 96 & 82 & 2 & $<1$ \\
\hline 4 & Cameroon & 2 & 27 & 8 & 4 & 90 & 69 \\
\hline 5 & Chad & $<1$ & 10 & 10 & 19 & 94 & 72 \\
\hline 6 & Congo & 30 & 66 & 46 & 23 & 25 & 12 \\
\hline 7 & Côte d'Ivoire & 7 & 46 & 36 & 23 & 57 & 31 \\
\hline 8 & DR Congo & $<1$ & 11 & 7 & 13 & 93 & 76 \\
\hline 9 & Ethiopia & 2 & 24 & 47 & 72 & 52 & 4 \\
\hline 10 & Gambia & $<1$ & 24 & 15 & 14 & 84 & 61 \\
\hline 11 & Ghana & 12 & 52 & 18 & 18 & 70 & 30 \\
\hline 12 & Guinea & 6 & 30 & 30 & 22 & 64 & 48 \\
\hline 13 & Guinea-Bissau & 6 & 19 & 9 & 12 & 85 & 69 \\
\hline 14 & Kenya & 3 & 37 & 15 & 17 & 82 & 46 \\
\hline 15 & Lesotho & $<1$ & 8 & $<1$ & 6 & 99 & 86 \\
\hline 16 & Liberia & $<1$ & 5 & 2 & 3 & 98 & 93 \\
\hline 17 & Malawi & $<1$ & 12 & 42 & 46 & 49 & 38 \\
\hline 18 & Mali & 2 & 23 & 25 & 30 & 73 & 47 \\
\hline 19 & Mauritania & 11 & 40 & 31 & 50 & 58 & 11 \\
\hline 20 & Namibia & 17 & 79 & 60 & 16 & 23 & 5 \\
\hline 21 & Nigeria & 4 & 29 & 80 & 66 & 16 & 6 \\
\hline 22 & Rwanda & $<1$ & 14 & 10 & 9 & 89 & 77 \\
\hline 23 & Sao Tome \&Principe & 25 & 65 & 19 & 9 & 55 & 26 \\
\hline 24 & Senegal & 2 & 37 & 5 & 24 & 93 & 39 \\
\hline 25 & Sierra Leone & $<1$ & 13 & 23 & 39 & 77 & 48 \\
\hline 26 & Sudan & 16 & 49 & 13 & 19 & 71 & 32 \\
\hline 27 & Tanzania & $<1$ & 17 & 77 & 74 & 22 & 9 \\
\hline 28 & Uganda & 2 & 19 & 36 & 48 & 62 & 33 \\
\hline 29 & Zambia & 2 & 41 & 22 & 32 & 76 & 27 \\
\hline 30 & Zimbabwe & 6 & 52 & 59 & 39 & 35 & 9 \\
\hline
\end{tabular}

Source: Adapted from [4]

\section{Curbing Inequalities and Improving WASH Services in SSA}

Achieving SDG 6 means everyone must have at least basic access to WASH services irrespective of wealth status, location, sex, religion, etc. However, WASH data are usually not disaggregated under these dimensions. Although global, regional and national estimates are usually provided separately for access to WASH services by wealth quintile and location, hardly do we have combined estimates for the trio, which makes it difficult to have a general picture of the progress in WASH services and how much efforts is needed to actualize the SDG 6, especially in SSA. A study estimated that the combined SDG WASH coverage for SSA was 4\%; which means that an estimated 921.6 million people lacked combined SDG coverage [15]. Similarly, a study revealed that only $11 \%$ of the Nigerian population had access to combined WASH services [14]. The disaggregated data by wealth quintile however shows wide disparity between the poorest and the richest quintile. The coverage proportions were as follows: poorest $3 \%$, poor $6 \%$, middle $5 \%$, rich $9 \%$ and richest $32 \%$. The combined data show that SSA is far behind in actualizing the SDG 6.

In order to design effective strategies to curb the WASH inequalities and make significant progress, all countries in the region must carry out surveys on combined WASH services, which would provide the foundation for takeoff. Without adequate data, investment and other efforts could be misdirected to further increase the inequality gap in service provision. Also, the top-bottom approach to facilities provision should be changed to bottom-up approach. The people are the ones to use the WASH facilities and have to be involved in their conceptualization, to encourage them to use and maintain the facilities. For example, a study reported that in 2015 , about $46 \%$ and $38 \%$ of all water schemes and improved water points, respectively in Nigeria were in bad state due to lack of proper usage and maintenance [16].

Since it has been established that access to basic WASH services improves with increase in wealth status, therefore, poverty reduction programmes, which could pull the people from the poverty trap and empower them to be able to afford and provide their own WASH facilities should be developed. This should be complimented by adequate investment and management of funds allocated for WASH services, especially for the bottom 40. This implies that all forms of mismanagement and corruption in the WASH sector should be eliminated or ameliorated. In addition, all countries in the region should develop adequate institutional and policy framework for WASH where they do not exist, detailing the responsibilities of all relevant government ministries, agencies, departments and other stakeholders, to avoid conflict of responsibilities and negative inter agencies rivalries, which 
could be inimical to WASH development. Furthermore, countries should encourage the development and use of lowcost but effective WASH technologies that meet both the financial status and cultural affinity of the people to promote general acceptance, usage and maintenance.

The cost of water has also been blamed for poor access to basic water supply in some countries. Therefore, efforts should be directed to reduce the cost of water, especially for the bottom 40 (poor and poorest), who are less empowered to pay for high water tariffs. For example, a study reported that despite the availability of boreholes in Yenagoa, some of the households per capita per day water usage were low (20 litres) due to high cost of water and poor disposal income [17]. Furthermore, agencies saddled with WASH provision should carryout routine and preventive maintenance of WASH facilities such as pipe network leak detection and repairs, careful billing of users and adequate monitoring and evaluation of services to ensure that set objectives and targets are met.

For any government policy to be effective, the people must be carried along. Hence, public education and information on the benefits and consequences of WASH services must be adequately disseminated to the public. This will build trust between government and the people and facilitate smooth implementation of government policies on WASH services. In addition, focus of governments in the region should be directed to bridging all forms of inequalities in WASH services, particularly between the rich and poor. The needs of women and girls, the vulnerable and those not served in all societies in the region should be considered as top priority if SSA hopes to meet the SDG 6 and not repeat its failures during the MDG era. It is therefore recommended that further studies be conducted on other levels of WASH disparities (urban and rural; men and women; able and disable) in SSA. These studies would provide the needed base data to guide policy formulation to eliminate all forms of disparities in WASH services and the attainment of the SDG 6.

\section{Conclusion}

The study has shown that the poor in SSA is disproportionately disadvantaged in WASH services. The richest quintile in all countries in the region has the best WASH services, as the coverage analysis has shown. Also, the t-test statistic has revealed that there was significant different in access to basic WASH services between the richest quintile and poorest quintile, as shown in the respective statistical test for WASH services. Furthermore, the combined rate of WASH services in SSA was very low. In fact, some countries recorded decline in access either to basic water services or sanitation or both, from 2000-2017. This scenario paints a gloomy picture on the actualization of the SDG 6. To avoid missing the target, all countries in the region should triple their current efforts in the WASH sector and adopt some of the recommendations made above. Since, there is no golden bullet that can fix all WASH challenges in all countries in the region; each country should design workable interventions that best suit its peculiarities. At the end, if the region fails to meet the SDG 6 targets, at least significant progress would have been achieved and a better foundation laid for the future.

\section{References}

[1] UNICEF (2012). Water, Sanitation and Hygiene (WASH) in Schools, A Companion to the child friendly schools manual, https://www.unicef.org/publications/files/CFS_WASH_E_web .pdf.

[2] Ohwo, O (2017). Households' Sanitation and Hygiene Practices in Yenagoa, Bayelsa State, Nigeria, Port Harcourt Journal of Social Sciences, Vol. 7 No 1: 185-197.

[3] UNICEF and WHO (2015). Progress on sanitation and drinking water: 2015update and MDG assessment [online] files.unicef.org/.../Progress_on_Sanitation_and_Drinking_Wa ter_2015_Update_pdf [Accessed July 25, 2020].

[4] UNICEF and WHO (2019). Progress on household drinking water, sanitation and hygiene 2000-2017, Special focus on inequalities, New York, USA.

[5] Ohwo, O and Agusomu, T. D (2018). Assessment of water, sanitation and hygiene services in sub-Saharan Africa, European Scientific Journal, 14 (35): 308-326.

[6] WHO and UNICEF (2017). Progress on Drinking Water, Sanitation and Hygiene: 2017 Update and SDG Baselines. Geneva: Licence: CC BY-NC-SA 3.0 IGO.

[7] World Bank (2017a). Reducing inequalities in water supply, sanitation, and hygiene in the era of the Sustainable Development Goals: Synthesis report of the WASH poverty diagnostic initiative, WASH synthesis report, World Bank, Washington, DC.

[8] Ohwo, O (2019). Dimensions of Inequality in Urban and Rural Water, Sanitation and Hygiene Services in Sub-Saharan Africa, European Scientific Journal, 15 (8): 144-162.

[9] World Bank (2017b). WASH Poor in a Water-Rich Country: A Diagnostic of Water, Sanitation, Hygiene, and Poverty in the Democratic Republic of Congo, World Bank, Washington, DC.

[10] The Gambia Bureau of Statistics (2019). The Gambia Multiple Indicator Cluster Survey 2018, Survey Findings Report, Banjul, The Gambia: 1-694.

[11] Adams, E. A and Smiley, S. L (2018). Urban-rural water access inequalities in Malawi: implications for monitoring the Sustainable Development Goals, Natural Resources Forum, DOI: $10.1111 / 1477-8947.12150: 217-226$.

[12] World Bank (2018). Reaching for the SDGs: The untapped potential of Tanzania's water supply, sanitation, and hygiene sector, WASH Poverty Diagnostic, World Bank, Washington, DC.

[13] Armah, F. A, Ekumah, B, Yawson, D. O, Odoi, J. O, Afitiri, A and Nyieku, F. E (2018). Access to improved water and sanitation in sub-Saharan Africa in a quarter century, Heliyon 4 e00931. doi: 10.1016/j.heliyon.2018.e00931: 1-32.

[14] National Bureau of Statistics (2018). National outcome routine mapping of water, sanitation and hygiene service levels, Nigeria: summary of survey finding, 2018. 
[15] Roche R, Bain R, Cumming O (2017). A long way to goEstimates of combined water, sanitation and hygiene coverage for 25 sub- Saharan African countries. PLoS ONE 12 (2): e0171783. doi: 10.1371/journal.pone.0171783.

[16] World Bank (2017c). A Wake Up Call: Nigeria Water Supply, Sanitation, and Hygiene Poverty Diagnostic, WASH Poverty Diagnostic, World Bank, Washington, DC.
[17] Ohwo, O and Abotutu, A (2014). Access to potable water supply in Nigerian cities: evidence from Yenagoa metropolis, American Journal of Water Resources, 2 (2): 31-36. 